\title{
Hypertension in Geriatric Population: Study in a Rural Community, Jamalpur, Bangladesh
}

Kabirul Hasan Bin Rakib ${ }^{*}$, Nazim Al Azad ${ }^{2}$, Nazmul Hoque Munna ${ }^{3}$, Md. Saiful Islam Patwary ${ }^{4}$, Abu Saleh Md. Sirajum Munir ${ }^{5}$, Mohammad Nadim Hasan ${ }^{6}$, Rabeya Bosri ${ }^{7}$, Manzurul Chowdhury ${ }^{8}$, Hanif Mohammad ${ }^{9}$

${ }^{1}$ Resident Physician (RP), Department of Medicine, Mugda Medical College Hospital, Mugda, Dhaka, Bangladesh

${ }^{2}$ Assistant Professor, Department of Medicine, Mugda Medical College Hospital, Mugda, Dhaka, Bangladesh

${ }^{3}$ Assistant Professor, Department of Neurology, Mugda Medical College Hospital, Mugda, Dhaka, Bangladesh

${ }^{4}$ Assistant Professor, Department of Medicine, Chandpur medical college, Chandpur, Cumilla, Bangladesh

${ }^{5}$ Assistant Professor, Department of Medicine, Chandpur Medical College, Chandpur, Cumilla, Bangladesh

${ }^{6}$ Assistant professor, Department of Medicine, Sheikh Hasina Medical College, Jamalpur, Bangladesh

${ }^{7}$ Assistant Registrar Gynae and Obstetrics department, Mugda Medical College Hospital, Mugda, Dhaka, Bangladesh

${ }^{8}$ Assistant professor, Department of Gastroenterology, Mymensingh Medical College, Mymensingh, Bangladesh

${ }^{9}$ Professor \& Head, Department of Medicine, Shaheed Suhrawardy Medical College (ShSMC), Dhaka, Bangladesh

DOI: $10.36347 /$ sjams.2021.v09i01.009

| Received: 13.12.2020 | Accepted: 22.12.2020 | Published: 09.01.2021

*Corresponding author: Dr. Kabirul Hasan Bin Rakib

Abstract

Original Research Article

Background: Hypertension is of great concern due to its role in the causation of coronary heart disease, stroke and other vascular complications. Community-based screen can improve the detection and treatment of Hypertension. As fewer studies have been undertaken in rural Bangladesh, it was decided to assess the prevalence, awareness, treatment, and control of hypertension particularly among the geriatric age group rural dwellers. The aim of this study was to find out the prevalence and awareness of hypertension among geriatric age group to assess the adequacy of hypertension control and treatment, to see awareness and treatment pattern of hypertension among them in a rural area of Bangladesh. Methods \& Materials: This was a descriptive, cross sectional and observational study. The study period was extended from $10^{\text {th }}$ May, 2013 to $10^{\text {th }}$, November, 2013 for a period of 6 months. A total of 200 geriatric people were included in the study from Fazilpur village of Jamalpur district. Categorical variables ware reported as percentage and correlation was carried out using the chi-square test (X2-test) through determining the association of different variables by SPSS software version-16. Main outcome measure: patients related variables: age, sex, weight, and smoker or not and main outcome variables: prevalence of hypertension, its awareness, visit to registered physician, pattern of prescription follow, BP properly controlled or not. Result: Our present study has shown that $42.00 \%$ people have hypertension. It is more common among male $(22.50 \%)$ than female $(19.50 \%)$, study population was 200 of them male were (95) and female were (105). The ratio of male and female were almost equal. Among HTN patients 48 were preciously diagnosed and 36 was diagnosed during the study as spot diagnosis. Most HTN patients are in the age group of 60-69 years (total 60) and $71.42 \%$ of all hypertensive are of this age group. Average BMI of HTN patient is $24.30 \%$ in case of male and $22.86 \%$ in case of female. Hypertensive ware found to be more smokers and consumers of betel nut and tobacco leaf than normal people. Village doctors made $62.50 \%$ of diagnoses for hypertension and there high rates $(42.85 \%)$ of undetected hypertension among the elderly. Conclusion: High rate of non detection and nonadherence to treatment was important findings of the study. The reasons for non adherence to treatment among geriatric population, mostly the people of low education need investigation. Screening the elderly for hypertension will benefit this group of people by reducing morbidity and mortality related to it and improves their quality of life. Here lies the room for behavior change communication and create awareness among general people about the importance of proper treatment of hypertension. Ensuring cheap supply of antihypertensive medication will also help persons from lower economic status.

Keywords: Hypertension, geriatrics, exploration, prevalence.

Copyright $\odot 2021$ The Author(s): This is an open-access article distributed under the terms of the Creative Commons Attribution 4.0 International License (CC BY-NC 4.0) which permits unrestricted use, distribution, and reproduction in any medium for non-commercial use provided the original author and source are credited.

\section{INTRODUCTION}

Aging is an inevitable part of life and brings along two inconvenient events: physiologic decline and disease state [1]. Hypertension is an important risk factor for cardiovascular morbidity and mortality, particularly in the elderly. It is a significant and often asymptomatic chronic disease, which requires optimal 
Kabirul Hasan Bin Rakib et al; Sch J App Med Sci, Jan, 2021; 9(1): 47-53

control and persistent adherence to prescribed medication to reduce the risks of cardiovascular and renal disease [2]. Some disabilities like senile cataract, glaucoma, bony changes affecting mobility, diabetes, hypertension, failure of special senses etc. are inevitable with ageing. Study of these physical and psychological changes which are incident to old age is called gerontology and the care of the aged is called clinical gerontology or geriatrics [3]. More people in both high and low income regions are living longer than ever before. The net increase of older population worldwide is about one million every month, two thirds of them being from the low income countries [4]. Population ageing has grown into a 'defining global issue' and concerns have emerged regarding development policy interventions appropriate for older people, especially in the area of elderly health problems and health care [5]. Bangladesh, with one of the highest population densities $(985 / \mathrm{km} \mathrm{sq})$ in the world, is projected to experience a dramatic growth in the absolute number of its population aged 60 years or older from the current level of approximately 7 million to 14 million by 2020 [6]. Very little is known about the health of the aged and its problems in Bangladesh. Developing countries, like Bangladesh, are likely to face an enormous burden of Non communicable diseases in future and of these diseases, hypertension is one of the most important treatable causes of mortality and morbidity in the elderly population [7, 8]. Further, high blood pressure (BP) is a modifiable risk factor for cardiovascular disease (CVD). Data, from the Framingham Heart Study showed 12increasing cardiovascular morbidity with increasing systolic or diastolic pressure in those aged 65 and over [9]. One of the cornerstones of the primary prevention of CVDs has been screening for high BP and anti-hypertensive drug treatment [10]. The benefits of anti-hypertensive drug therapy for older persons have been clearly established. Prior studies have shown that anti-hypertensive drug treatment for older hypertensive persons confers highly significant and clinically relevant reductions in cardiovascular morbidity and mortality rates [11]. Nevertheless, a considerable percentage of older persons with hypertension are not detected or arc not adequately treated for hypertension [12]. Measures should be taken to diagnose hypertension and prevent or postpone its complications in this age group as the burden of hypertension is bound to increase due to increasing life expectancy rates. However, very few studies have been regarding this issue. So, the current study is carried out to document the prevalence, awareness, treatment and control of hypertension, along with the conception regarding its control, adoption of life style measures and to search for morbidity related to Hypertension among geriatric individuals living in the rural community in selected region of Bangladesh.

\section{OBJECTIVES}

General Objective

- To study the prevalence and awareness of hypertension among geriatric age group in rural population of Bangladesh.

\section{Specific Objective}

- To assess the level of hypertension in elderly patient.

- To see adequacy of control and treatment of Hypertension.

- To see awareness of the target group regarding effects and importance of control of Hypertension.

\section{Methodology and Materials}

This was a descriptive, cross sectional observational study. The study was conducted in a rural community-Fazilpur of Madarganj Uupazilla under the district of Jamalpur, Bangladesh. The study was carried out over a period of 6 months from $10^{\text {th }}$ may 2013 to $10^{\text {th }}$ November 2013. . Prior permission was taken for this study from the Ethical Committee of Mymensingh Medical College Hospital, Mymensingh, Bangladesh. The sample size was determined using following formula. $\mathrm{n}-\left(\mathrm{Z}^{2} \times \mathrm{P} \times \mathrm{q}\right) / \mathrm{d}^{2} \bullet$ where $\mathrm{Z}=$ Standard normal deviate, $\mathrm{z}=1.96, \mathrm{p}=$ Prevalence of HTN in Bangladesh. The prevalence of HTN in Bangladesh is not known, the value of prevalence will be considered as $50 \%$. So, $\mathrm{p}$ will be 0.5. So, $\mathrm{q}=(1-\mathrm{p})=0.50$, and $\mathrm{d}=$ Desired accuracy or degree of allowable error (here $10 \%$ of $\mathrm{p})=0$. 05. So, $\mathrm{n}=\left\{\left(1.96 / /^{\mathrm{x}} \mathrm{O} \cdot 5^{\mathrm{x}} \mathrm{O} .5\right\} /(0.05) 2\right.$ Or. $\mathrm{n}=200$. Sampling was done by simple random method. There are about 7000 Population in Fazilpur village, of them about 400 are of geriatric age group. 200 geriatric persons were randomly selected who fulfill the inclusion criteria. Data were collected from the adult people of Fazilpur village of Madaganj Upazilla under Jamalpur district who meet the inclusion criteria through a preplanned questionnaire Cases were interviewed with the aid of Bangla version standardized questionnaire containing - items elicited age, sex and other demographic variable. The Bangla version of standardized questionnaire was translated by standard back translation method from validated standardized questionnaire and it has been followed the steps, that is forward translation, backward translation, pre-testing and final version. The interviewed questions were including data on age, sex, Weight, smoking, tobacco chewing, co-morbid illness. The information was recorded in interviewer-administered questionnaire. All data were entered, checked, rechecked and scrutinized by the principal investigator following standard procedure and was analyzed by SPSS Programme version 20 to ensure the result of this study. 


\section{RESULT}

The present study intended to explore the hypertension among geriatric population in rural Bangladesh through collecting data from Fazilpur village under Jamalpur district. Their age frequency $115(57.50 \%)$ were from $60-69$ years. $65(32.50 \%)$ were from $70-79$ years $15(7.50 \%)$ were from $80-89$ years, and $05(2.50 \%)$ were 90 years and above. This study was carried on 200 cases. Among them, 95 (47.50\%) were male and $105(52.50 \%)$ were female patients. Among the 200 cases $84(42 \%)$ patient were Hypertensive, among them $48(24 \%)$ patients were previously diagnosed Hypertensive and $36(18 \%)$ were newly diagnosed. Whereas $116(58 \%)$ were free of hypertension. Among the 84 Hypertensive population $45(53.57 \%)$ was male and $39(46.43 \%)$ was female. Among the 95 elderly male $45(47.36 \%)$ were found Hypertensive and among the 105 elderly female 39 $(37.14 \%)$ were hypertensive. Among the hypertensive geriatric population most were in the age group of 6069 years the frequency declined gradually during the subsequent years. Among the HTN patient $53(63 \%)$ were of grade 2 and 10 (12\%) were of grade 3. Among all 84 patients were previously diagnosed and 36 were newly diagnosed. Among the 48 known hypertensive 17 were controlled properly and remaining 31 were not adequate controlled. Among the study population of 200 randomly selected people literate was only 35 $(17.50 \%)$ and $165(82.50 \%)$ was illiterate. Increased body mass index (BMI) is an established important related factor of HTN. This study revealed an average BMI of 23.63 among the hypertensive people which was 24.30 among the male and 22.857 among the female of geriatric age group; whereas among normotensive population the average BMI was found to be 21.50 that was 18.29 among the male and 20.35 among the female normotensive people. Related factor of the HTN were found in the study: Smoking, Taking betel nut, Tobacco leaf chewing and Alcoholism are common habits. Taking betel nut and Tobacco leaf chewing are mostly the provisions of the female group and smoking is totally not, but the male group along with these two bad habits is involved in smoking. Overall $54.76 \%$ of the hypertensive was smoker, $60.71 \%$ used to take betel nut, and $65.47 \%$ was tobacco leaf chewer and nobody was found to be Alcoholic Out of the literate people 13 were previously diagnosed as a case of hypertension and 6 were diagnosed during the study period and a total 19 literate person were Hypertensive. Literate hypertensive people were more adhere with the antihypertensive medication and the advice given to them by the physician than the illiterate people. Among the 13 literate $8(61.54 \%)$ were adherent to medication, and $5(38.46 \%)$ were not; on the other hand out of 35 illiterate hypertensive only 5 (14.29\%) were adherent to medication and the rest $30(85.71 \%)$ were totally not adhere.. Among 200 study population a total $95(47.50 \%)$ People were found to know previously something about blood pressure, among them $90(45 \%)$ gave history of blood pressure measurement previously. $48(53.30 \%)$ persons were diagnosed as HTN patient through those measurement. $33(68.75 \%)$ people gave history of taking measure for their Hypertension but as high as $15(31.25 \%)$ were totally ignorant about its management. out of 33 hypertensive $29(60.41 \%)$ receiving some prescriptions for their Hypertension of which 11 (22.91\%) prescription was done by registered physician, and 18 $(37.5 \%)$ was prescribed by village doctors or quack. 4 people gave the history of taking alternative or herbal remedy for HTN. 21 (72.41\%) people was provided advice by the prescriber regarding life style modifications. Interestingly the total 48 persons who were found to be hypertensive previously; 30 were found to be diagnosed by village doctors and 18 were diagnosed by qualified physician. The hypertensive patients were advised in a haphazard manner to adopt life style like stopping smoking, stopping tobacco chewing, salt restriction, avoiding excess fat in diet, to have walk or mild to moderate exercise daily, to meditate or pray and avoiding stress and also some unauthentic advice like taking citrus fruits or tamarinds as traditional belief. Adherence to drugs was a major concern of this study.

Table-1: Demographic characteristics of the studied population $(\mathbf{n}=\mathbf{2 0 0})$

\begin{tabular}{|l|l|l|}
\hline Age & $\mathbf{n}$ & $\mathbf{( \% )}$ \\
\hline $60-90$ & 115 & 57.5 \\
\hline $70-79$ & 65 & 32.5 \\
\hline $80-89$ & 15 & 7.5 \\
\hline $90<$ & 5 & 2.5 \\
\hline Male & 95 & 47.5 \\
\hline Female & 105 & 52.5 \\
\hline Literate & 35 & 17.5 \\
\hline Illiterate & 165 & 82.5 \\
\hline BMI & \\
\hline Male & 24.3 \\
\hline Female & 22.86 \\
\hline
\end{tabular}


Table-2: The habitual status of the geriatric population $(n=200)$

\begin{tabular}{|l|l|l|l|}
\hline Sex & Habit & Frequency & \% \\
\hline Male & Smoking & 66 & 73 \\
\hline & Taking betel nut & 50 & 52 \\
\hline & Tobacco leaf chewing & 45 & 47.36 \\
\hline & Alcoholism & 0 & 00 \\
\hline Female & Smoking & 0 & 00 \\
\hline & Taking betel nut & 95 & 90.40 \\
\hline & Tobacco leaf chewing & 85 & 80 \\
\hline & Alcoholism & 0 & 00 \\
\hline
\end{tabular}

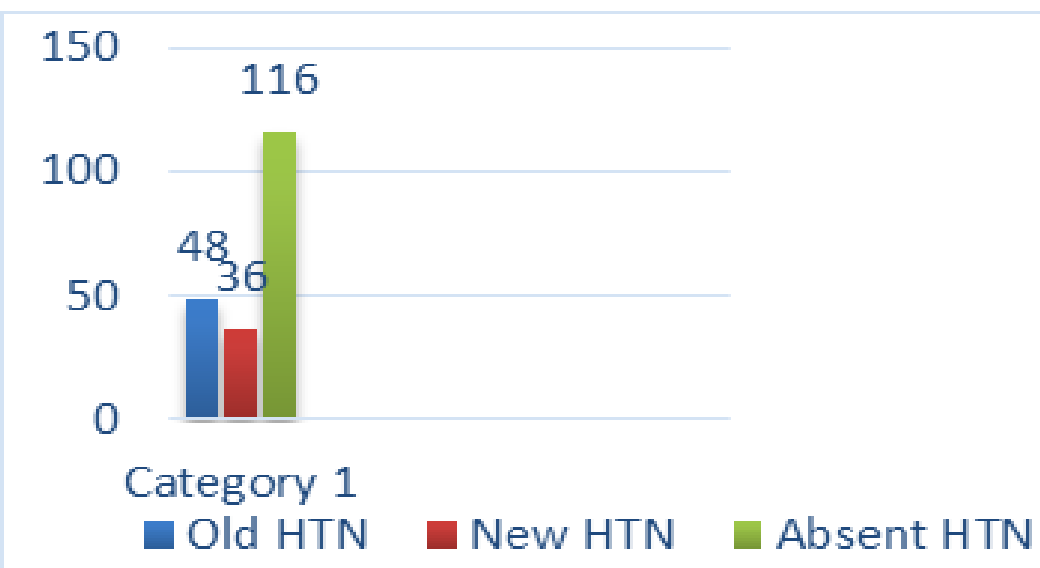

Fig-1: Status of blood pressure of the studied population $(n=200)$

Table-3: Male and female distribution among hypertensive $(n=200)$

\begin{tabular}{|l|l|l|}
\hline Sex & n & \% \\
\hline Male & 45 & 53.57 \\
\hline Female & 39 & 46.43 \\
\hline
\end{tabular}

Table-4: The HTN at different age group of irrespective of sex $(n=200)$

\begin{tabular}{|l|l|l|l|}
\hline Age in years & Frequency & \% of the total HTN patients & \% of the total study population \\
\hline $60-69$ & 60 & 71.428 & 30 \\
\hline $70-79$ & 19 & 22.62 & 9.5 \\
\hline $80-89$ & 5 & 5.95 & 2.5 \\
\hline 90 and above & 00 & 00 & 00 \\
\hline
\end{tabular}

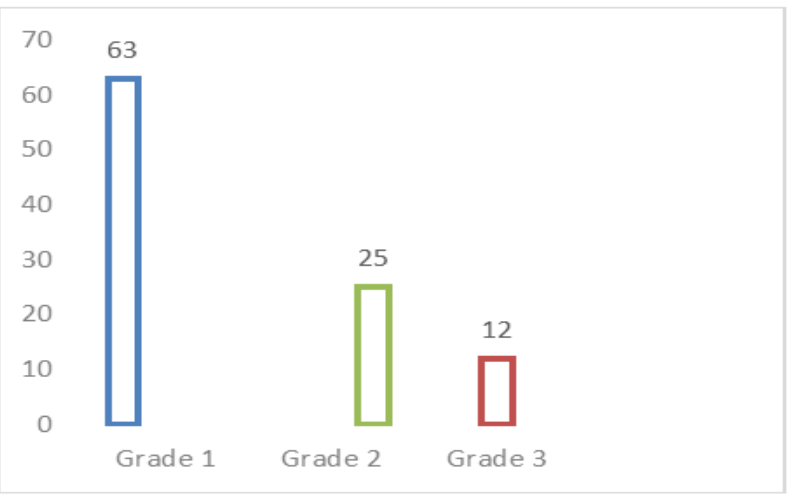

Fig-2: The percentage of the severity of HTN $(n=200)$

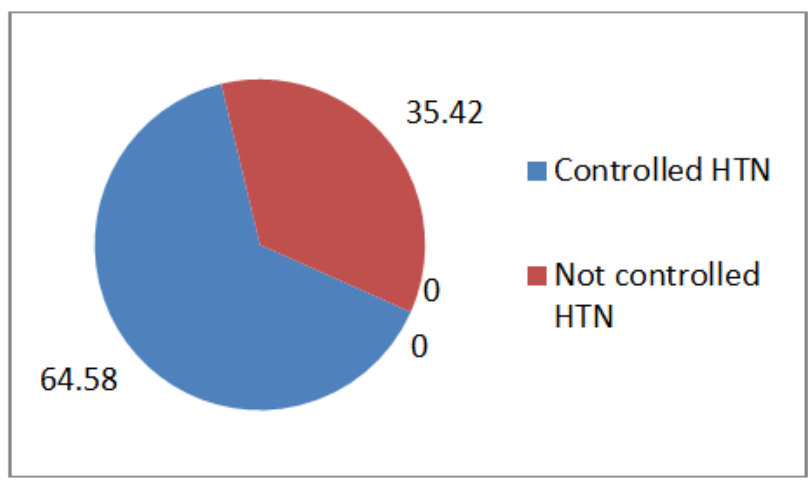

Fig-3: Showing proportion of controlled and uncontrolled HTN $(\mathbf{n}=\mathbf{2 0 0})$ 
Kabirul Hasan Bin Rakib et al; Sch J App Med Sci, Jan, 2021; 9(1): 47-53

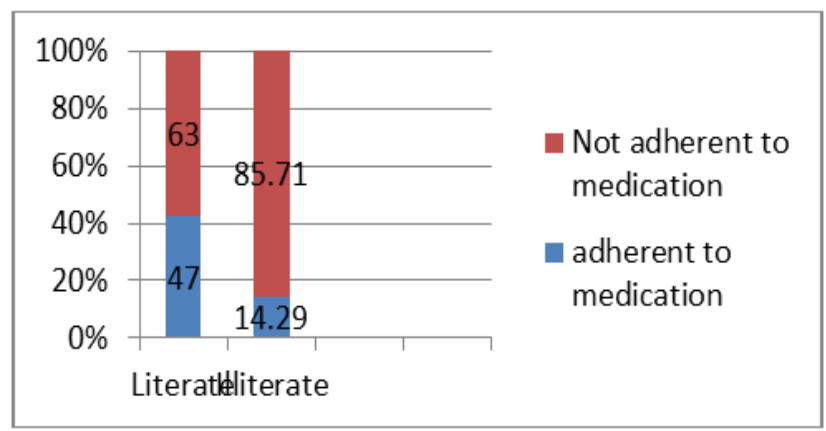

Fig-4: Proportion of medication adherence among literate \& hypertensive population $(n=200)$
Table-5: The level of HTN diagnosis. $(n=200)$

\begin{tabular}{|l|l|l|}
\hline Level of diagnosis & $\mathrm{n}$ & $\%$ \\
\hline At village doctor level & 30 & 62.5 \\
\hline At qualified physician level & 18 & 37.5 \\
\hline
\end{tabular}

Table-6: The associated co morbidity among the geriatric population $(n=200)$

\begin{tabular}{|l|l|l|}
\hline Co-morbidity & $\mathbf{n}$ & $\mathbf{\%}$ \\
\hline IHD & 14 & 29.16 \\
\hline Heart failure & 4 & 8.33 \\
\hline CKD & 3 & 6.25 \\
\hline Stroke & 9 & 18.75 \\
\hline Obesity & 8 & 16.6 \\
\hline RHD & 3 & 625 \\
\hline DM & 13 & 27,08 \\
\hline
\end{tabular}

Table-7: Status of life style advice given among the hypertensive $(\mathbf{n}=\mathbf{2 0 0})$

\begin{tabular}{|l|l|l|}
\hline Advice & $\mathrm{n}$ & $\%$ \\
\hline Stopping smoking? & 33 & 100 \\
\hline Stopping tobacco chewing? & 25 & 75.75 \\
\hline Adopting salt restriction? & 20 & 60.60 \\
\hline To avoid excess fat in diet? & 25 & 75.75 \\
\hline To have walk or mild to moderate exercise daily? & 12 & 36.36 \\
\hline To avoid alcohol, if you are alcoholic? & -- & -- \\
\hline Meditation or pray and avoiding stress & 20 & 60.60 \\
\hline Others, like taking citrus fruit or tamarinds & 15 & 45.45 \\
\hline
\end{tabular}

Table-8: Adherence to drug treatment by the previous known hypertensive $(\mathrm{n}=\mathbf{2 0 0})$

\begin{tabular}{|l|l|l|}
\hline Manner of adherence & $\mathrm{n}$ & $\%$ \\
\hline People not taking the drug at all & 19 & 39.58 \\
\hline People taking the drug regularly? & 13 & 27.09 \\
\hline People taking the drug irregularly? & 16 & 33.33 \\
\hline
\end{tabular}

\section{DiscUSSION}

In the present study, out of 200 individuals examined 84 individuals (including 48 old hypertensive cases) were found to be suffering from hypertension and over all pre valence rate of hypertension was found to be $-42 \%$ among both sexes. However the prevalence of hypertension was $53.57 \%$ arnong males (45 cases in 95 males) and $43.43 \%$ among females (39 cases in 105 females). This study indicates high prevalence of hypertension (42\%) among elderly population. This is much higher than $16.34 \%$ as described by Gurav RB, Kartikeyan S [13] and even higher than $37.5 \%$ found by Khokkar A et al., [14] However our finding was corroborative with Swami et al., [15] and $48 \%$ by Prakash et al., [16]. There was minimum male female difference in prevalence of hypertension which was $53.57 \%$ in male and $46.43 \%$ in female elderly people. In this study about $47.37 \%$ of the males and $37.14 \%$ of the females were hypertensive in the elderly age group but among all the hypertensive $53.57 \%$ were males and $46.43 \%$ were female. This gives minimum gender biased information in the elderly population. It is known that prevalence of hypertension increases with age [17]. Our study also found the same result. During analysis excluding persons 80 years and above resulted in more significance of association. This finding probably indicates that after attaining a certain age the rising tendency of prevalence of hypertension reaches a plateau. However this finding cannot be generalized due to small number of persons over 80 years. People of the Indian subcontinent and Bangladesh are genetically more prone to suffer from cardiovascular diseases and hypertension is already an established risk factor of it. Thus high prevalence of hypertension doubles the dilemma over aging population. Proper treatment of hypertension and keeping the blood pressure under control reduces the risk of cardiovascular diseases. The present study revealed that though $68.75 \%$ population with HTN took some sort of measures taking HTN as a problem or disease that might hamper their lives but as high as $31.25 \%$ of hypertensive were not adhere at all to its management. Although $60.42 \%$ hypertensive people received some kind of prescriptions for their Hypertension, mostlof which obviously were not quality assured because most of the prescriptions were made by unqualified village doctors which was almost $54.55 \%$ of all HTN patients and $37.5 \%$ of the total prescriptions made. Moreover the warning aspect of this study was that as high as $39.58 \%$ of hypertensive was not taking any sort of medications for hypertension. Most of the people $(39.58 \%)$ not taking any medication 
thinking that it would not pose any serious problem to them. A certain number of $08.33 \%$ people were on herbal remedy for their pressure control. It is to mention that $33.33 \%$ of hypertensive didn't take medications regularly. So many factors run by hands for not taking drugs or taking in a useless irregular manner. Unawareness, unavailability, financial constrains and forgetfulness are the main factors to mention. The practice of taking medication was significantly higher among literate persons. Low awareness among illiterates indicates the need for behavioral change communication activity. However another revelation was that a large group of people from lower income group were not taking medication. Thus not only lack of awareness, financial constrains is also an important reason. Besides most of the elderly population are tendency of prevalence of hypertension reaches a plateau. However this finding cannot be generalized due to small number of persons over 80 years. Peoples of the Indian subcontinent and Bangladesh are genetically more prone to suffer from cardiovascular diseases and hypertension is already an established risk factor of it. Thus high prevalence of hypertension doubles the dilemma over aging population. Proper treatment of hypertension and keeping the blood pressure under control reduces the risk of cardiovascular diseases. The present study revealed that though $68.75 \%$ population with HTN took some sort of measures taking HTN as a problem or disease that might hamper their lives but as high as $31.25 \%$ of hypertensive were not adhere at all to its management. Although $60.42 \%$ hypertensive people received some kind of prescriptions for their Hypertension, most of which obviously were not quality assured because most of the prescriptions were made by unqualified village doctors which was almost $54.55 \%$ of all $\mathrm{H} 1 \mathrm{~N}$ patients and $37.5 \%$ of the total prescriptions made. Moreover the warning aspect of this study was that as high as $39.58 \%$ of hypertensive was not taking any sort of medications for hypertension. However another revelation was that a large group of people from lower income group were not taking medication. Thus not only lack of awareness, financial constrains is also an important reason .Significant association of hypertension with cardiovascular diseases, cardiovascular accident and obesity was also documented. Actually hypertension, cardiovascular diseases, cardiovascular accident, diabetes mellitus, CKD and obesity are under the same umbrella of modem non communicable diseases (NCD). This study also revealed rheumatic heart disease (RHD) as the associated problem in the geriatric population along with Hypertension as RHD prophylaxis and awareness was not of concern at the childhood period of these senior citizens. Association of hypertension with the social health is the new domain of the present study. The inability to do normal day to day work for self maintenance often indicates the inability of the person to live rest of his/her life with at least minimum comfort. Respondents had subjective feeling of dissatisfaction that indirectly reflects the quality of life of the helpless elderly persons. Thus hypertension imparts a bigger impact on the quality of life. Increased morbidity associated with hypertension affects not only physical health but also the social health of the elderly persons. In our study sample, $68.75 \%$ of People took measure for their Hypertension. However, only $35.42 \%$ of them had their blood pressure adequately controlled (SBP $<140 \mathrm{mmHg}$ and DBP $<90 \mathrm{mmHg}$ ) through adopting all measures like lifestyle and proper medication. About $42.85 \%$ of the respondents were newly diagnosed with hypertension. Although these proportions are dissimilar to those reported from other developing countries [18]. In European countries, these levels range from $52.7 \%$ in Germany to $70 \%$ in Sweden. In Canada and USA the awareness rate is $83 \%$ and $87.3 \%$ respectively $[19,20]$. In these studies, the degree of awareness of hypertension was higher (81\%) than those reported by the India study [21]. Among treated hypertensive individuals in this study, about $35.42 \%$ had blood pressure controlled. These data are also similar to those reported by Liau et al., This study focused on some special points like the habits of the rural population and their increased association among the hypertensive patients, as it was found that overall $54.76 \%$ of the hypertensive were smoker, $60.71 \%$ used to take betel nut, and $65.47 \%$ were tobacco leaf chewer. Advice provided by the health care providers was also an important aspect of this study and it revealed that salt restriction is not given so much emphasis although smoking, tobacco chewing, avoiding fatty food was emphasized though the rural people believe that taking citrus fruits and tamarinds may help control their Hypertension.

\section{Limitations OF THE STUDY}

This study was conducted over a limited period of time. Only the entitled patient's got opportunity participated in the study. So, the limited sample size, short duration, and a limited study area were the limitations of this study. So, with a large sample, vast area and large span of time, the study may be further conducted

\section{Conclusion and Recommendations}

High rate of non detection and non-adherence to treatment was important findings of the study. The reasons for non adherence to treatment among geriatric population, mostly the people of low education need investigation. Screening the elderly for hypertension will benefit this group of people by reducing morbidity and mortality related to it and improves their quality of life. Here lies the room for behavior change communication and create awareness among general people about the importance of proper treatment of hypertension. Ensuring cheap supply of antihypertensive medication will also help persons from lower economic status. 


\section{REFERENCES}

1. Abrassl B. The biology and physiology of aging. West J Med, 1990; 153:641-645.

2. Hamilton GA. Measuring adherence in a hypertension clinical trial. Eur J Cardiovasc Nurs. 2003; 2:219-228.

3. Park K. Park's Textbook of Preventive and Social Medicine. 18th Edition, M/s Banarsidas Bhanot, Jabbalpur, India. 2005; 434-435.

4. Gorman M. Global Ageing- the nongovernmental organization Mole in the developing world. Int $\mathbf{J}$ Epidemiol. 2002; 31:782-785.

5. Biswas P, Kabir ZN, Nilsson J, Zaman IS. Dynamics of health care seeking behavior of elderly people on rural Bangladesh. Intetnational Journal of Ageing and Later Life. 2006; 1: 69-89.

6. Solomons NW. Health and Ageing. In Flores R, Gillepsie S, (eds.), Health and Nutrition: Emerging and Reemerging Issues in Developing Countries. Washington D.C.: International Food Policy Research Institute, 2001.

7. Kearney PM, Whelton M, Reynolds K, Muntner $\mathrm{P}$, Whelton PK, He J. Global burden of hypertension: analysis of worldwide data. The lancet. 2005 Jan 15;365(9455):217-23.

8. Chobanian A V, Bakris OL, Black HR, Cushman WC, Green LA, Izzo JL, Jones DW, Materson BJ, Oparil S, Wright JT. The Seventh Report of the Joint National Committee on Prevention, Detection, Evaluation, and Treatment of High Blood Pressure: the JNC 7 report. JAMA. 2003; 289:2560-2572.

9. Levy D, Larson MG, Vasan RS, Kannel WB, Ho KK. The progression from hypertension to congestive heart failure. Jama. 1996 May 22;275(20):1557-62.

10. Wassertheil-Smoller S, Anderson G, Psaty BM, Black HR, Manson J, Wong N, Francis J, Grimm R, Kotchen T, Langer R, Lasser N. Hypertension and its treatment in postmenopausal women: baseline data from the Women's Health Initiative. Hypertension. 2000 Nov;36(5):780-9.

11. Lloyd-Jones DM, Evans JC, Levy D. Hypertension in adults across the age spectrum: current outcomes and control in the community. JAMA. 2005; 294:466- 472.
12. Ong KL, Tso A W, Lam KS, Cheung BM. Gender difference in blood pressure control and cardiovascular risk factors in Americans with diagnosed hypertension. Hypertension. 2008; 51:1142-1 148 .

13. Gurav RB, Kartikeyan S. Problem of geriatric population in an urban area Bombay Hospital Journal. 2002 Jan; 44(1).

14. Khokhar A, Mehra M. Lifestyle and morbidity profile of geriatric population in an urbans community of Delhi. Indian J Med Sci. 2001; 55:609-15.

15. Swami HM, Bhatia V, Dutt R, Bhatia SPS. A community based study of the morbidity profile among the elderly in Chandigarh, India. Bahrain Med Bull. 2002; 24(1):13-16.

16. Prakash R, Choudhary SK, Singh US. A Study of Morbidity Pattern among Geriatric Population in an Urban Area of Udaipur, Rajasthan. Indian J Community Med. 2004; 21(1):35-40.

17. Shapo L, Pomerleau J, McKee M. Epidemiology of hypertension and associated cardiovascular risk factors in a country in transition: a population based survey in Tirana City, Albania. Journal of Epidemiology \& Community Health. 2003 Sep 1;57(9):734-9.

18. Shapo L, Pomerleau J, McKee M. Epidemiology of hypertension and associated cardiovascular risk factors in a country in transition: a population based survey in Tirana City, Albania. Journal of Epidemiology \& Community Health. 2003 Sep 1;57(9):734-9.

19. Wilkins K, Campbell NRC, Joffres MR, McAlister FA, Nichol M, Quach S, Johansen HL, Tremblay MS: Blood Pressure in Canadian adults. Health Rep. 2010, 21:37-46.

20. Hypertension Study Group. Prevalence, awareness, treatment and control of hypertension among the elderly in Bangladesh and India: a multicentre study. Bulletin of the World health Organization. 2001;79(6):490-500.

21. Wyatt SB, Akylbekova EL, Wofford MR, Coady SA, Walker ER, Andrew ME, Keahey WJ, Taylor HA, Jones DW. Prevalence, awareness, treatment, and control of hypertension in the Jackson Heart Study. Hypertension. 2008 Mar 1;51(3):650-6. 